\title{
Chemical variability of Vicia L. seed oils: incidence on phylogenetic relationships
}

\author{
Bechkri $\mathbf{S}^{1,2^{*}}$, Benabdallah $\mathrm{A}^{3}$, Yilmaz Mustafa $\mathrm{A}^{4,5}$, Tarhan $\mathrm{A}^{4}$, Boutekrabt Benhadja \\ $\mathbf{L}^{2}$, Khelifi $\mathbf{D}^{1,6}$ \\ 1 : Laboratoire de Génétique Biochimie et Biotechnologies Végétales. Université Frères Mentouri \\ Constantine 1. Constantine, Algeria \\ 2 : Agence Thématique de Recherche en Biotechnologies et Sciences AgroAlimentaires (ATRBSA). \\ Constantine, Algeria \\ 3: Laboratory of Biodiversity and Ecosystem Pollution. Faculty of life and Nature sciences. \\ University Chadli Bendjedid, El Tarf.. Algeria \\ 4: Dicle University Science and Technology Research and Application center (DUBTAM). Dicle \\ University Diyarbakır. Turkey \\ 5: Department of Pharmaceutical Chemistry. Faculty of Pharmacy. Dicle University Diyarbakır. \\ Turkey \\ 6 : Ecole Nationale Supérieure de Biotechnologie (ENSB). Université Salah Boubnider \\ Constantine, Algeria
}

\begin{abstract}
*Corresponding Author: BECHKRI S, Laboratoire de Génétique Biochimie et Biotechnologies Végétales. Université Frères Mentouri Constantine 1. Route de Ain El Bey, Constantine; Email: s.bechkri@gmail.com
\end{abstract}

\begin{abstract}
Legume seeds are known to be a source of protein, vitamins, essential organic minerals and fatty acids. Their high protein content makes them a valuable natural and inexpensive alternative to the soybean. Seeds fatty acids of genotypes belonging to nine Vicia L. taxa collected in Algeria were extracted by Soxhlet and their composition was determined by Gas Chromatography coupled with FIame Ionization Detection (GC-FID). In order to assess phylogenetic relationships between taxa on intra and interspecific levels, fatty acids profiles were used as a chemotaxonomic marker. Oil yields were between 0.67 and $2.40 \%$. A total of 27 fatty acids were identified, varying from 9 to 20 compounds. The proportion of unsaturated fatty acids varies from 70.67 to $91.749 \%$ where the linloleic acid is predominant. While the saturated fatty acids content is between 8.60 and $29.33 \%$ with the predominance of palmitic acid. Our results demonstrate the quality of the genotypes, which contain fatty acids of great nutritional interests. Indeed, Omega 3-fatty acids, which rate can reach $12.187 \%$ in our taxa, are Poly UnSaturated Fatty Acids associated with many health benefits, such us cardiovascular ones. Indeed, the results demonstrate the nutritional quality of obtained oils and opens up perspectives to explore other compounds. Finally, the hierarchical classification revealed two major clusters where the taxonomic boundaries of the genus are well defined at subgeneric and sectional levels. It is also an important step to suggest the species as a new industrial crop for the animal feed and production of proteins and oils widely used in food industries
\end{abstract}

Keywords: Algeria; Fatty acids; Vicia; GC-FID; Phylogeny.

\section{Introduction}

Legume seeds are recognized to be a rich source of protein, vitamins, essential organic minerals and fatty acids (FA) (Pastor Cavada et al. 2009). Their high protein content makes them a valuable natural and inexpensive alternative to the soybean. The widespread use of vetch seeds also makes them an important source of fat for ruminant and non-ruminant diet. The importance of FA lies in their role as a precursor for the biosynthesis of eicosanoids which is an important bio-regulator for many cellular metabolic processes. It is well established that CLA or other PUSFA increase pregnancy rates of cows. Milk and meat that contain high quantities of CLA can benefit for human health (Belury 2002). 
In addition, anti-glycemic and anti-cholesterolemic legume seeds effects are due to dietary fiber and FA content (Pirman and Stibilj 2003). Therefore, FA attracted attention for their value for industrial purposes and also for their use as chemotaxonomic significance.

In Algeria, the genus Vicia is distributed in the whole country and is represented by 26 species. It includes many species and subspecies with morphological characteristics that are so subtly different which makes difficult to discriminate taxa within the genus. Despite ongoing researches, the few existing reports on Vicia L. taxa were conducted either on morphological or on molecular aspects, which did not cover the entire classification of the species. Therefore, chemotaxonomy based on Fatty Acids Methyl Esters could help to resolve uncertainties not completely addressed by other approaches, such as molecular studies. As far as we know, there are no previous studies on the intraspecific chemical variability of Algerian Vicia L. taxa fatty acids oils and their nutritional values, although its place as animal feed in the agricultural areas of the arid regions of the Mediterranean countries is well demonstrated in the literature.

The aim of our study is to assess the chemovariability of FA profiling of Vicia L. taxa. This work, combined with those we carried out previously on the genetic diversity of Vicia species publications (Bechkri and Khelifi 2016, Bechkri and Khelifi 2017 a, b, Bechkri et al. 2018, Bechkri et al. 2019), would furnish complementary insight to envisage the management, selection and propagation of interesting chemotypes and genotypes. It is also an important step to suggest the species as a new industrial crop for the animal feed and production of proteins and oils widely used in food industries.

In the same time, the FA profiles were used as chemotaxonomical markers to establish phylogenetic relationships between the taxa at different taxonomic levels, as we mentioned in our previous publications, the taxonomic boundaries within the genus are controversial.

\section{Material and methods}

\section{Vicia seeds}

Twenty vetch populations randomly collected from their natural habitats in various bioclimatic conditions of Algeria were used in the current study. Origins and field information are given in Table 1. Taxonomic identification of accessions was verified by the morphology of plants grown from seeds as it is explained in Bechkri and Khelifi (2016).

Table 1. Passport data of investigated taxa

\begin{tabular}{lllll}
\hline Taxon & Code & Date of collection & Origin & Altitude (m) \\
\hline V. sativa subsp. consobrina & 14 & 1.6 .14 & El Bouni. Annaba & 28 \\
\hline V. sativa subsp. consobrina & 64 & 1.6 .14 & Azzaba. Skikda & 111 \\
\hline V. sativa subsp. consobrina & 86 & 13.6 .14 & Djbel el Ouehch Constantine & 880 \\
\hline V. sativa subsp. cordata & 13 & 26.5 .14 & El Kantra. Biskra & 584 \\
\hline V. sativa subsp. cordata & 42 & 28.5 .14 & Ain Abid. Constantine & 847 \\
\hline V. sativa subsp. cordata & 47 & 22.5 .14 & Frères Mentouri Constantine University & 604 \\
\hline V. sativa subsp. obovata & 10 & 27.5 .14 & Didouche Mourad. Constantine & 468 \\
\hline V. sativa subsp. obovata & 17 & 22.5 .14 & Chaab Ersas. Constantine & 563 \\
\hline V. sativa subsp. obovata & 22 & 2.6 .14 & Sigus. Oum El Bouaghi & 822 \\
\hline V. sativa subsp. obovata & 32 & 22.5 .14 & Chaab Ersas. Constantine & 562 \\
\hline V. narbonensis & 23 & 30.5 .14 & Hamma Bouziane. Constantine & 425 \\
\hline V. narbonensis & 55 & 27.5 .14 & Didouche Mourad. Constantine & 443 \\
\hline V. monantha subsp. calcarata & 18 & 3.6 .14 & Ain Taghrout. Bourdj Bou Areridj & 934 \\
\hline V. monantha subsp. calcarata & 78 & 20.5 .14 & Coudiat. Constantine & 633 \\
\hline V. monantha subsp. calcarata & 102 & & Frères Mentouri Constantine University & 604 \\
\hline V. leucantha & 100 & 10.6 .14 & INATAA. Constantine & 586 \\
\hline V. tenuifolia & 56 & 6.6 .14 & Ain Temouchent & 276 \\
\hline V. tenuifolia & 89 & 6.6 .14 & Sidi Khaled. Sidi Bel Abbes & 543 \\
\hline V. lutea subsp. vestita & 4 & 22.5 .14 & Frères Mentouri Constantine University & 604 \\
\hline V. lutea subsp. eu-lutea & 87 & 30.5 .14 & El Milia. Jijel & 28 \\
\hline
\end{tabular}




\section{Extraction of the seed oils}

The extraction of the seed oils was done according to Hara and Radin (1978) and to Emre et al. (2013), modified. The extraction of oils was done by Soxhlet (ISO-LAB) adopting the following approach: between 2 and 3 grams of finely ground seeds are deposited in cellulose extraction thimble (FILTER.LAB Barcelona, Spain). A piece of cotton is placed on it to prevent overflow of the sample and then the thimble is placed in a $250 \mathrm{ml}$ Soxhlet flask. For each sample, the oil is extracted with 350 $\mathrm{ml}$ of $\mathrm{n}$-hexane. The latter is brought to a boil then the temperature is lowered. To prevent the system from heating, its temperature is maintained at $8^{\circ} \mathrm{C}$ with a cryostat (LAUDA). The $500 \mathrm{ml}$ flask containing the sample is recovered after 6 hours, then, it is passing to the rotary evaporator (IKA RV 10) at a temperature of $41^{\circ} \mathrm{C}$ and $80 \mathrm{rpm}$, connected to a vacuum pump (V-700 BUCHI). When remaining between 25 and $30 \mathrm{ml}$ of hexane, the sample is recovered in a $50 \mathrm{ml}$ balloon and then passed again in the rotavap. to remove all hexane.

Oil yield

The oil yield is then calculated by relating the weight of the extract to the weight of crushed seeds. The result was expressed as the lipid percentage in the dry seed powder.

\section{Oil transesterification}

The FAME were prepared by transesterification by mixing n-hexane with the oil then adding KOH (2 $\mathrm{mol} / \mathrm{L}$ ), according to Alves et al. (2008). After centrifugation, the sample is left in the dark for 1 hour and a half.

\section{Fatty acids Methyl Esters analyses (FAME)}

The FAME were analyzed by GC-FID, according to Renna et al. (2014), modified, to determine FA constituents. A $1 \mathrm{~mL}$ sample from the supernatant was put into $\mathrm{GC}$ vials and injection was started immediately. A gas chromatography system (GC-2010 plus SHIMADZU) equipped with a flame ionization detector and a TR-CN 100 column (100 m x $0.25 \mathrm{~mm} \times 0.20 \mu \mathrm{m}$ ID) was used. Injection block temperature was set at $250^{\circ} \mathrm{C}$. The oven temperature was kept at $140^{\circ} \mathrm{C}$ for $5 \mathrm{~min}$, then ramped up from 140 to $240^{\circ} \mathrm{C}$ at $4^{\circ} \mathrm{C} / \mathrm{min}$, and finally held at $240^{\circ} \mathrm{C}$ for $20 \mathrm{~min}$. The injector (AOC-2Oi) is automated $(0.80 \mu \mathrm{l}$ per sample). Helium was used as carrier gas (flow rate $51.1 \mathrm{ml} / \mathrm{min}$, split ratio 1/50). FAME peaks were identified by comparing their retention times and spectra with standard mixture analyzed under the same conditions. FA composition was expressed as \% of total oil.

\section{Cluster analysis based on fatty acids composition}

Cluster analysis based on FA composition was performed with Euclidean Distances Matrix based on the Unweighted Pair-Group Method using Arithmetic Averages (UPGMA) by Statistica 6.0 software.

\section{Results \\ Oil yields}

The oil yield of Vicia seeds varies from 0.67 to $2.40 \%$ (table 2). In the sativa complex, of the ten genotypes studied, an accession obovata has the highest oil yield (accession 22). The lowest yield is observed in an accession of obovata also. In the three accessions of $V$. monantha subsp. calcarata, a difference is observed in the oil yield of the three accessions. The only accession of $V$. leucantha is among the richest oil samples with a yield $(2.16 \%)$. While, we recorded similar oil yield in both $V$. tenuifolia accessions. 
Bechkri et al. 2021. Genet. Biodiv. J, Special issue (Characterization and valorisation of Plants), 25-38

Table 2. Seeds oils yields in accessions investigated

\begin{tabular}{|c|c|c|}
\hline Taxon & Code & Oil yield $(\%)$ \\
\hline V. sativa subsp. consobrina & 14 & 1.35 \\
\hline V. sativa subsp. consobrina & 64 & 1.50 \\
\hline V. sativa subsp. consobrina & 86 & 2.23 \\
\hline V. sativa subsp. cordata & 13 & 1.73 \\
\hline V. sativa subsp. cordata & 42 & 1.8 \\
\hline V. sativa subsp. cordata & 47 & 1.77 \\
\hline V. sativa subsp. obovata & 10 & 1.53 \\
\hline V. sativa subsp. obovata & 17 & 1.57 \\
\hline V. sativa subsp. obovata & 22 & 2.40 \\
\hline V. sativa subsp. obovata & 32 & 1.03 \\
\hline V. narbonensis & 23 & 1.53 \\
\hline V. narbonensis & 55 & 1.30 \\
\hline V. monantha subsp. calcarata & 18 & 2.32 \\
\hline V. monantha subsp. calcarata & 78 & 0.67 \\
\hline V. monantha subsp. calcarata & 102 & 1.30 \\
\hline V. leucantha & 100 & 2.16 \\
\hline V. tenuifolia & 56 & 1.24 \\
\hline V. tenuifolia & 89 & 1.2 \\
\hline V. lutea subsp. vestita & 4 & 1.33 \\
\hline V. lutea subsp. eu-lutea & 87 & 1.13 \\
\hline
\end{tabular}

\section{Fatty acids analysis}

Chromatograms of some accessions are presented in figure 1. A total of 27 different FA were identified (table 3), varying from 9 to 20 FA.

(a)

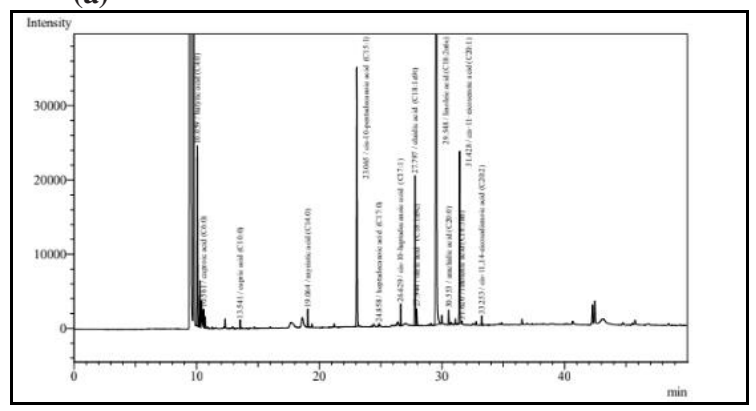

(c) (b)

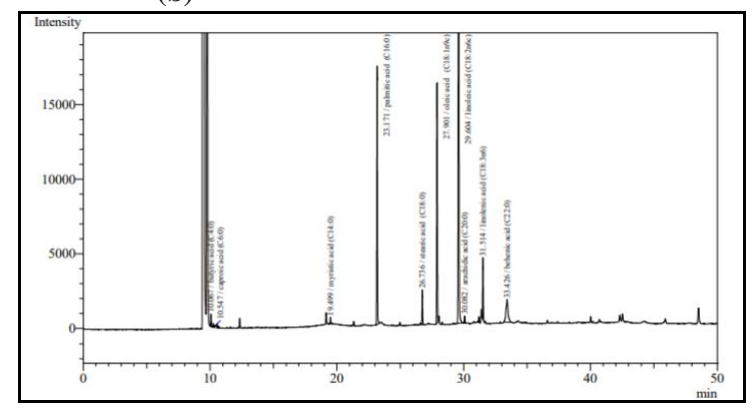

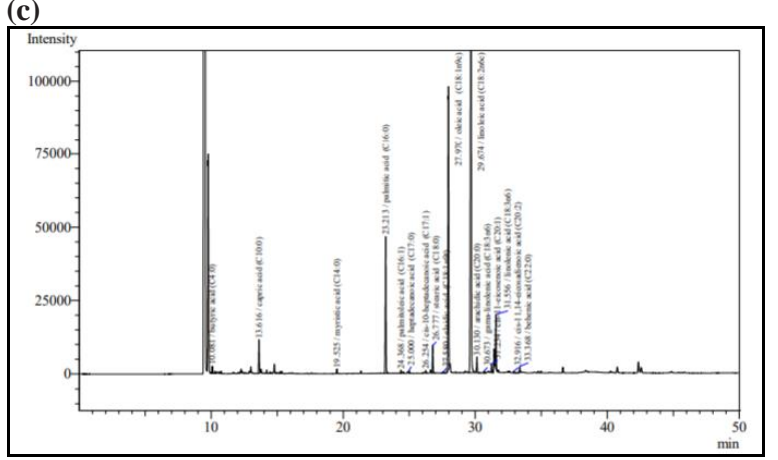

Fig 1. Chromatograms of some accessions obtained by GC-FID of fatty acids
(a) : accession 100
(b) accession 18
(c) accession 55 
Bechkri et al, 2021. Genet. Biodiv. J, Special issue (Characterization and valorisation of Plants), 25-38

Table 3. Fatty acids composition of Vicia taxa studied

\begin{tabular}{|c|c|c|c|c|c|c|c|c|c|c|c|c|c|c|c|c|c|c|c|c|}
\hline FA (\%) & 14 & 64 & 86 & 13 & 42 & 47 & 10 & 17 & 22 & 32 & 23 & 55 & 18 & 78 & 102 & 100 & 56 & 89 & 4 & 87 \\
\hline Butyric acid & 3.91 & 4.70 & 4.81 & 7.722 & 2.84 & - & 0.94 & 0.078 & 0.265 & 0.227 & 0.406 & 0.464 & 0.698 & - & 0.537 & 5.975 & 0.168 & - & 0.104 & - \\
\hline Caproic acid & - & - & - & 2.312 & 0.359 & 0.096 & - & - & - & - & - & - & 0.294 & - & 0.132 & 0.567 & 0.098 & 0.161 & - & 0.129 \\
\hline Caprylic acid & - & - & 0.311 & - & - & - & - & - & - & - & - & - & - & 0.255 & - & - & - & - & - & - \\
\hline Capric acid & 0.352 & 1.802 & 3.593 & 2.932 & - & - & - & - & - & - & - & 2.526 & - & - & - & 0.331 & - & - & - & - \\
\hline Undecanoic acid & - & - & 1.131 & 0.81 & - & 0.082 & - & - & - & - & - & - & - & - & - & - & - & - & - & - \\
\hline Myristic acid & 0.917 & 0.176 & - & 0.17 & - & 0.223 & 0.602 & 0.423 & 0.328 & 0.8 & 0.523 & 0.284 & 0.403 & 1.637 & 0.471 & 0.68 & 0.909 & 1.213 & 0.493 & 1.048 \\
\hline Pentadecanoic acic & 0.249 & - & - & 0.238 & - & 0.239 & 0.194 & 0.168 & 0.156 & 0.231 & 0.123 & - & - & 0.268 & 0.263 & - & 0.359 & 0.317 & 0.246 & 0.27 \\
\hline $\begin{array}{l}\text { Cis-10 } \\
\text { pentadecanoic acid }\end{array}$ & - & - & 14.126 & - & - & - & - & - & - & - & - & - & - & - & - & 9.51 & - & - & - & - \\
\hline Palmitic acid & 11.737 & 12.457 & - & 10.73 & 12.902 & 12.739 & 13.913 & 11.028 & 13.445 & 11.913 & 10.677 & 10.41 & 15.075 & 14.525 & 13.308 & - & 13.065 & 14.369 & 11.563 & 11.932 \\
\hline Palmitoleic acid & - & 0.233 & - & 0.06 & 0.077 & - & - & 0.075 & 0.063 & - & 0.135 & 0.212 & - & - & - & - & 0.078 & - & 0.075 & - \\
\hline Heptadecanoic acid & 0.19 & 0.246 & - & 0.149 & 0.151 & 0.183 & 0.169 & 0.162 & 0.153 & 0.169 & 0.19 & 0.18 & - & - & 0.212 & 0.082 & 0.217 & 0.249 & 0.225 & 0.154 \\
\hline $\begin{array}{l}\text { Cis-10 } \\
\text { heptadecanoic acid }\end{array}$ & 0.145 & - & 4.023 & 0.052 & 0.1 & 0.104 & - & - & - & 0.127 & - & 0.172 & - & - & - & 0.776 & 0.208 & - & - & - \\
\hline Stearic acid & 3.188 & 4.455 & - & 2.675 & 2.469 & 3.607 & 2.798 & 3.309 & 2.835 & 2.429 & 2.702 & 2.124 & 1.994 & 1.637 & 1.561 & - & 1.939 & 2.296 & 2.644 & 2.271 \\
\hline Elaidic acid & - & 0.265 & 19.507 & - & - & - & - & - & - & - & - & 0.155 & - & - & - & 0.596 & - & & - & - \\
\hline Oleic acid & 17.102 & 16.497 & 0.071 & 14.016 & 19.396 & 19.572 & 14.522 & 21.835 & 14.279 & 16.35 & 35.882 & 24.866 & 14.17 & 12.87 & 16.05 & 0.647 & 20.072 & 18.449 & 15.495 & 9.989 \\
\hline Linolelaidic acid & - & 0.169 & 0.894 & 0.064 & - & - & 0.068 & - & 0.064 & - & - & - & - & - & - & - & - & & - & - \\
\hline Linoleic acid & 51.554 & 48.884 & 46.746 & 45.282 & 51.653 & 50.364 & 56.344 & 51.659 & 56.982 & 55.728 & 41.16 & 51.756 & 58.77 & 62.948 & 60.734 & 67.911 & 50.206 & 48.024 & 60.299 & 61.764 \\
\hline Linolenic acid & 8.055 & 4.866 & - & 8.578 & 8.019 & 9.073 & 8.43 & 7.876 & 9.774 & 9.384 & 3.614 & 4.032 & 3.799 & - & 4.454 & 0.078 & 10.317 & 11.984 & 7.344 & 9.499 \\
\hline Arachidic acid & 0.897 & - & 0.282 & 1.234 & 1.136 & 1.852 & 1.217 & 1.395 & 1.313 & 1.108 & 1.151 & 1.379 & 0.461 & 0.666 & 0.738 & 0.617 & 0.811 & 1.323 & 0.934 & 0.975 \\
\hline $\begin{array}{l}\text { Gamma-linolenic } \\
\text { acid }\end{array}$ & - & - & - & 0.297 & 0.178 & 0.344 & 0.11 & - & - & 0.151 & 0.083 & 0.14 & - & 5.194 & 0.35 & - & 0.44 & 0.587 & - & 0.253 \\
\hline Heneicosanoic acid & - & - & 0.816 & - & - & - & - & - & - & - & - & - & - & - & - & - & - & - & - & - \\
\hline Homolinoleic acid & 1.322 & 0.308 & - & - & 0.283 & - & 0.308 & 0.982 & - & 0.976 & - & 0.119 & - & - & 0.542 & 0.349 & 0.649 & 0.465 & 0.258 & 1.386 \\
\hline $\begin{array}{l}\text { Cis-11, 14, 17- } \\
\text { ecosatrienoic acid }\end{array}$ & - & - & - & - & - & 1.049 & - & 0.133 & - & - & - & - & - & - & - & - & - & 0.203 & - & - \\
\hline $\begin{array}{l}\text { Cis-13, 16- } \\
\text { docosadienoic acid }\end{array}$ & - & - & - & 0.379 & - & - & - & 0.455 & - & - & 0.368 & - & - & - & - & - & - & 0.359 & - & - \\
\hline $\begin{array}{l}\text { Cis-11-eicosenoic } \\
\text { acid }\end{array}$ & 0.381 & 3.708 & 3.694 & 1.942 & 0.444 & 0.475 & 0.384 & 0.422 & 0.345 & 0.409 & 0.593 & 0.67 & - & - & 0.647 & 6.882 & 0.464 & - & 0.321 & 0.329 \\
\hline Behenic acid & - & 0.284 & - & 0.358 & - & - & - & - & - & - & - & 0.51 & 4.336 & - & - & - & - & - & - & - \\
\hline $\begin{array}{l}\text { Cis-4, 7, 10, 13, 16, } \\
\text { 19-docosahexaenoic } \\
\text { acid }\end{array}$ & - & - & - & - & - & - & - & - & - & - & 2.393 & - & - & - & - & - & - & - & - & - \\
\hline $\begin{array}{l}\text { Number of fatty } \\
\text { acids }\end{array}$ & 14 & 16 & 13 & 20 & 14 & 15 & 14 & 15 & 13 & 14 & 15 & 17 & 10 & 9 & 14 & 14 & 16 & 14 & 13 & 13 \\
\hline$\sum$ SFA & 21.44 & 24.12 & 10.95 & 29.33 & 19.857 & 19.021 & 19.833 & 16.563 & 18.495 & 16.877 & 15.649 & 17.877 & 23.261 & 18.988 & 17.222 & 8.601 & 17.349 & 19.928 & 16.209 & 16.779 \\
\hline$\sum$ MUFA & 17.628 & 20.703 & 41.421 & 16.07 & 20.017 & 20.151 & 14.906 & 22.332 & 14.687 & 16.886 & 36.61 & 26.075 & 14.17 & 12.87 & 16.697 & 23.411 & 20.822 & 18.449 & 15.891 & 10.318 \\
\hline$\sum$ PUFA & 60.931 & 54.227 & 47.64 & 54.6 & 60.133 & 60.83 & 65.26 & 61.105 & 66.82 & 66.239 & 47.618 & 56.047 & 62.569 & 68.142 & 66.08 & 68.338 & 61.612 & 61.622 & 67.901 & 72.902 \\
\hline$\sum$ UFA & 78.559 & 74.930 & 89.061 & 70.67 & 80.150 & 80.981 & 80.166 & 83.437 & 81.507 & 83.125 & 84.228 & 82.122 & 76.739 & 81.012 & 82.777 & 91.749 & 82.434 & 80.071 & 83.792 & 83.22 \\
\hline USFA / SFA & 3.66 & 3.11 & 8.13 & 2.41 & 4.04 & 4.26 & 4.04 & 5.04 & 4.41 & 4.93 & 5.38 & 4.59 & 3.30 & 4.27 & 4.81 & 10.67 & 4.75 & 4.02 & 5.17 & 4.96 \\
\hline$\omega 6$ & 52.876 & 49.361 & 47.64 & 46.022 & 52.114 & 50.708 & 56.83 & 53.096 & 57.046 & 55.879 & 41.611 & 52.015 & 58.77 & 68.142 & 61.084 & 68.26 & 51.295 & 48.97 & 60.557 & 63.403 \\
\hline$\omega 3$ & 8.055 & 4.866 & 0 & 8.578 & 8.019 & 10.122 & 8.43 & 8.009 & 9.774 & 9.384 & 6.007 & 4.032 & 3.799 & - & 4.454 & 0.078 & 10.317 & 12.187 & 7.344 & 9.499 \\
\hline$\omega 6 / \omega 3$ & 6.564 & 10.144 & & 5.365 & 6.499 & 5.010 & 6.741 & 6.630 & 5.837 & 5.955 & 6.927 & 12.901 & 15.470 & & 13.714 & & 4.972 & 4.018 & 8.246 & 6.675 \\
\hline
\end{tabular}




\section{Saturated fatty acids}

The SFA content varied from 8.601 (V. leucantha) and $29.33 \%$ (V. sativa subsp. cordata), with the predominance of palmitic acid which was observed at the highest level in an accession of $V$. monantha subsp. calcarata and at the lowest amount in an accession of $V$. narbonensis. The highest rate of butyric acid is recorded in a V. sativa subsp. cordata sample, the lowest rate is also found in the sativa complex but in another taxon. This FA was not identified in 4 accessions. It should be noted that the caproic acid was not detected in 11 accessions out of the 20 studied. Its highest and lowest rates are registered in samples of $V$. sativa subsp. cordata.

Caprylic acid has been identified in only two accessions, as for the capric acid, it was recorded in 6 samples with the highest rate in a population of $V$. sativa subsp. consobrina. Special attention can be attributed to undecanoic acid, which was detected only in a single accession ( $V$. sativa, subsp. consobrina), with a rate of $1.131 \%$. As for myristic acid, the highest rate of undecanoic acid is detected in a genotype of $V$. monantha subsp. calcarata, its lowest one in a genotype of $V$. narbonensis. Accordingly, saturated acids with low molecular weight (caproic, caprylic, capric) can be found in certain accessions; but not in others.

Note that heneicosanoic acid is only found in the sample 86 ( $V$. sativa subsp. consobrina). Behenic acid was found in only 4 samples with the highest level in an accession of $V$. monantha subsp. calcarata.

\section{Total UnSaturated fatty acids (TUSFA)}

The TUSFA content is much higher than that of SFA. It varies from 70.67 to $91.749 \%$, registered in the single accession of $V$. leucantha (table 3).

\section{MonounSaturated fatty acids (MUSFA)}

Six MUFA were detected out of 27 obtained. The lowest level is observed in an accession of $V$. lutea subsp. eu-lutea; the highest rate is detected in a sample of $V$. sativa subsp. consobrina.

The cis-10 pentadecanoic acid is recorded only in a $V$. sativa subsp. consobrina genotype as well as in the only accession of $V$. leucantha. Palmitoleic acid is found in 10 genotypes with its highest and lowest levels detected in the complex sativa but in two different taxa, which is also valid for cis-10 heptadecanoic acid.

Elaidic acid occurs only in 3 genotypes with its highest level in an accession of $V$. sativa subsp. consobrina.

Special mention should be made for oleic acid, which is the most common MUSFA in the genotypes studied. Its highest rate was obtained in an accession of $V$. narbonensis. Finally, cis-11 eicosenoic acid is registered in 17 accessions, its highest level is detected in the single accession of V. leucantha. The cis-10-pentadecanoic acid is observed in only two samples: V. sativa subsp. consobrina and the single accession of $V$. leucantha.

Total Polyunsaturated fatty acids (TPUFA)

The TPUFA varies from 47,618 to $72,902 \%$ (table 3). The highest amount is found in a genotype of $V$. lutea, when the lowest one is obtained in a sample of $V$. narbonensis. Linolelaidic acid was only observed in 5 samples. Linoleic acid is the only FA found in all genotypes and is the most common among PUFA. It varies from 41.16 to $67.911 \%$ (in the only accession of $V$. leucantha). This accession has the lowest level of linolenic acid. $\gamma$-linolenic acid was not identified in 9 samples, its highest level was found in an accession of $V$. monantha subsp. calcarata.

Cis 11, 14, 17 ecosatrienoic acid was only identified in 3 accessions. Cis 13, 16-docosadienoic acid was observed in only 4 samples. Cis 4-7-10-13-16-19 docosahexaenoic acid was only identified in a $V$. narbonensis accession. The cis-13,16-docosadienoic acid is observed only in four accessions. 


\section{Cluster analysis based on fatty acids composition}

At the distance of 239.96, the dendrogram (figure 2), can be divided into two major clusters.

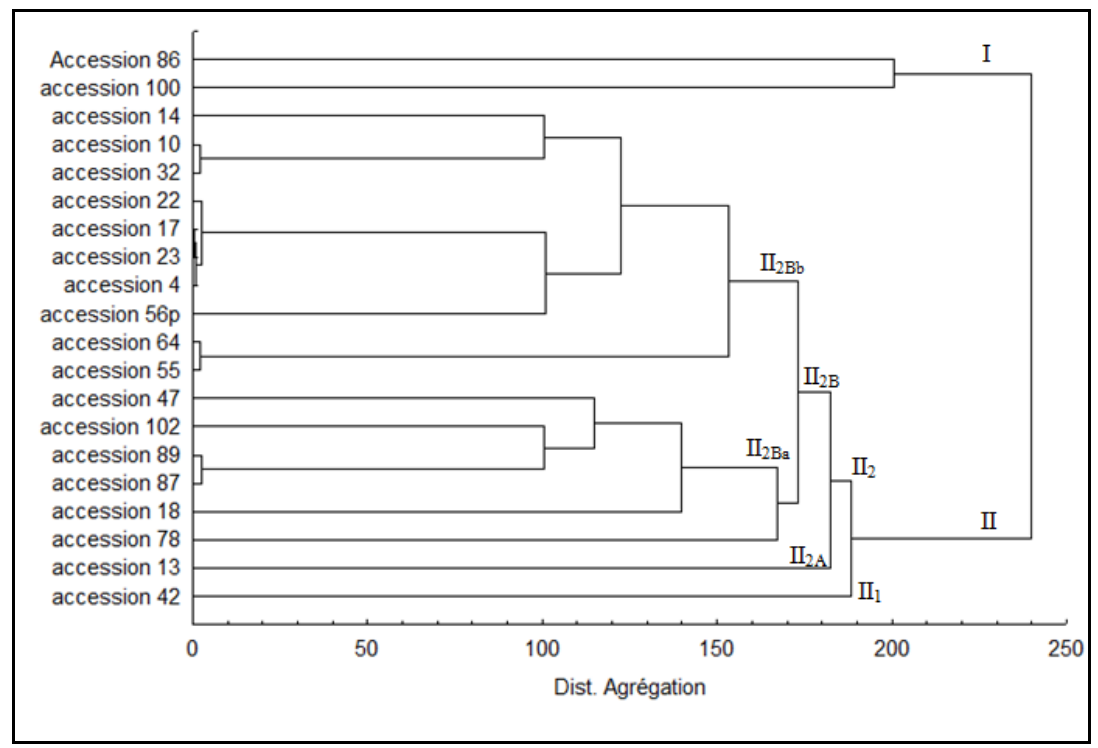

Figure 2. Cluster analysis based on fatty acids composition

In the subcluster $\mathrm{II}_{2} \mathrm{~B}_{\mathrm{a}}$, containing six samples, four of them belong to the subgenus Vicilla, section Cracca. The other two belong to the subgenus Vicia; a sample is part of the Vicia section and the second part of the Hypechusa section. In the subcluster $\mathrm{II}_{2} \mathrm{~B}_{\mathrm{b}}$, we find on one side two accessions belonging to the same subgenus and to the same section: V. narbonenis (Subgenus Vicia, section Narbonensis) and V. sativa subsp. consobrina (Subgenus Vicia, section Vicia). On the other side, three groups are defined: the first group contains three samples of the same species and therefore of the same genus, the same sub-genus and of the same section (subgenus Vicia, section Vicia), the second group contains an accession of the subgenus Vicilla and the section Cracca, the third group includes 4 accessions, the first of which belongs to the subgenus Vicia, section Hypechusa and the other three to the subgenus Vicia and to two different sections (Vicia and Narbonensis).

The largest distances corresponding to very distant samples in the clustering, is observed between two accessions belonging to the two subgenera (Vicia and Vicilla) and therefore to different sections and species. In parallel, the smallest distance is obtained between a sativa accession (subgenus Vicia, section Vicia) and an accession of Narbonensis (subgenus Vicia, section Narbonensis). At the same time, smaller distances are obtained between genotypes belonging to different sections (Narbonensis, Vicia and Hypechusa).

\section{Discussion}

The lowest and highest values of oil yields are observed in accessions belonging to different species. In addition, accessions belonging to the same taxon have different oil yields, as is the case with the three samples of $V$. monantha subsp. calcarata.

No literature exists reporting the FA profile of the different studied taxa. In addition, some FA identified in our accessions have not been found in previous publications. However, our results are in accordance with many works where USFA were higher than SFA, and PUSFA upper than MUSFA levels, as reported in the seeds of various legumes in different ecogeographical areas (Bagci et al. 2004 ; Pastor Cavada et al. 2009b; Renna et al. 2014). Moreover, our findings are in agreement with Bagci et al. (2004), who recorded that the main FA in legume seed are palmitic, oleic, linoleic and linolenic acids. 
From the other hand, the ratio SFA/USFA is superior than those reported for Chineese (Akpinar et al., 2001), and Turkish vetch (Mao et al., 2015). Besides, higher ratios of SFA/USFA are observed in our samples compared to previous studies (Renna et al., 2014). According to Mao et al. (2015), the seeds are low in lipid with a ratio of USFA/SFA up to 3.30-3.66, which means that the seeds have accumulated more USFA primarily as linoleic, oleic and $\alpha$-linolenic acids.

The oleic/linoleic FA ratio was usually reported to be less than one in the seeds of many Vicia taxa or Leguminosae (Pastor Cavada et al. 2009b).

The lowest level of palmitic acid was observed in a $V$. narbonensis accession with the highest seed diameter (5.50 \pm 0.42$)$. The lowest level of linolenic acid was observed in the single accession of $V$. leucantha which has a mean diameter compared to other taxa (Bechkri et al. 2017a). our findings concord to Holman (1981), who observed that the proportion of palmitic and linolenic acids diminishes, as the diameter of peas increases during growth period

\section{Total Saturated Fatty Acids}

SFA values obtained in our study are different to those reported by Bagci et al. (2004). Our results join previous data where palmitic and stearic acids are major SFA (Akpinar et al. 2001, Pastor-Cavada et al. 2009b). But, their concentrations are lower than those of Kaplan et al. (2014). In our study, the lower value was observed in the only sample of $V$. leucantha. While for. Renna et al. (2014), the seeds of $V$. narbonensis showed a significantly lower TSFA concentration.

Odd-chain SFA (pentadecanoic, heptadecanoic, non-decanoic acids) detected in our samples, were not reported previously. However, Lauric acid which is not detected in our accessions was reported by Akpinar et al. (2001).

Low molecular acids from the SFA were absent or present at trace levels in the studied vetch oils, while margaric and margaroleic acids were not detected in our samples.

The arachidic acid was higher than $1 \%$, which is different from finding of Bagci et al. (2004), where it was lower than $1 \%$. These researchers also reported that the highest and lowest absolute concentrations of this FA were observed in $V$. sativa subsp. amphicarpha and $V$. narbonensis (which is not our case).

The content of myristic and pentadecanoic acids in common vetch seed in our study is lower than those of chineese (Mao et al., 2015), and Turkish samples (Akpinar et al. 2001).

According to Bagci et al. (2004), lignoceric acid was not detected in the seeds of V. narbonensis and $V$. villosa when vetch seeds showed significant differences in the concentration of lignoceric acid which is not observed in our genotypes.

Palmitic acid is a steady lipid of several Leguminosae and is the most important SFA in vegetable oils and especially in Vicia seeds (Renna et al. 2014). These findings agree with our results since the most important SFA found in our samples is the palmitic acid. Its amount was relatively low comparing with the values reported by Renna et al. (2014) and by Andrzejewska et al. (2016). The latter reported that the level of this FA in lupine is much higher than that of vetch.

Our results are in agreement to many previous works which reported that the stearic acid is the second most abundant FA in vetch seeds (Akpinar et al. 2001, Bagci et al. 2004, Pastor Cavada et al. 2009b, Emre et al. 2011, Renna et al. 2014).Their values are similar to those reported for the other Leguminousae (Bagci et al. 2004).

In our study, the richest sample in stearic acid is an accession of $V$. sativa subsp. consobrina, which concords to Emre et al. (2011), who noticed that the richest species in stearic acid is a subspecies of $V$. sativa. Besides, stearic acid was found in a low level in our samples, while it was more important in Turkish seeds (Akpinar et al. 2001). 
On the other side, Bagci et al. (2004), reported that the highest and lowest concentrations of behenic acid were observed in $V$. sativa subsp. amphicarpha and $V$. narbonensis. While, in our results, it was only revealed in 4 samples and with rates lower than $1 \%$ (except for a $V$. monantha subsp. calcarata accession). This result highlights a nutritional value of the samples since several studies revealed that oils with high levels of long chain SFA such as behenic acid may be difficult for the digesting enzymes in animals (Akpinar et al. 2001). No work in the literature has reported the presence of caproic, caprylic and capric acids, whereas these FA have been detected in our taxa.

\section{Total UnSaturated Fatty Acids (TUSFA)}

Our results show that TUSFA contents of the seeds oils are higher than the TSFA, which are higher than those found by Kaplan et al. (2014). In our study, we noticed an interesting rate of $91.74 \%$, which was not reported in the literature.

Indeed, according to Bagci et al. (2004), TUSFA content of Vicia species is lower than $70 \%$. While Bakoglu et al. (2017), reported that TUSFA of vetch taxa can reach $80.67 \%$. They also determined that TUSFA was included between 75.9 and $83.46 \%$, in earlier works, on different Leguminosae (Bakoglu et al., 2010).

Furthermore, TUSFA values were comparable to those previously reported for other taxa of the genus (Bagci et al. 2004; Pastor-Cavada et al. 2009b; Emre et al. 2011; Renna et al. 2014), even though some of these works did not consider the same taxa we studied. Our results are also consistent with works on related genera like Lathyrus, Lens, Pisum and Lupine (Bagci et al. 2004). Nevertheless, Akpinar et al. (2001) noticed that TUSFA content of vetche seeds, grown in Turkey, is under $60 \%$.

According to several studies, oils rich in oleic and linoleic acids are the most adaptable and also excellent edible oils. Oleic, linoleic and linolenic acids are major USFA in the present study. All the investigated taxa were richer in oleic and linoleic acids than in linolenic acid. Oleic and linoleic acids were determined to be the major USFA in some Leguminosae oil which is used as a food in some countries (Higuchi et al. 1982). Oleic acid is well represented being the third most abundant USFA, after linoleic and oleic acids, in all the samples here analyzed. Its highest rate was observed in an accession of $V$. tenuifolia, a result that has never been reported in the literature.

\section{MonoUnSaturated Fatty Acids (MUSFA)}

Oleic acid has a role in the prevention of cardiovascular risks. This FA was found to be the most abundant one in the vetch by Pastor Cavada et al. (2009b). Our findings join those of Emre et al. (2011), who revealed that the major MUSFA in Astragalus seeds of all taxa is oleic acid. The same result was found on vetch by Akpinar et al. (2001). Compared to all other detected FA, oleic acid showed the greatest differences among the studied seeds which also concord to the results of Renna $e t$ al. (2014), who noticed that the seeds of $V$. sativa contained significantly lower concentrations of oleic acid than $V$. narbonensis. In our results, the highest level of oleic acid was also noticed in an accession of $V$. narbonensis. In fact, according to previous studies conducted in Mediterranean regions (Bagci et al. 2004, Pastor Cavada et al. 2009b, Emre et al. 2011, Renna et al. 2014), the highest oleic acid content was recorded in $V$. narbonensis.

Palmitoleic acid did not show significant difference among the considered seeds, its lowest level is detected in a sample of $V$. sativa subsp. cordata. This is in accordance with Emre et al. (2011), who noticed that the lowest percentage of this FA is revealed in a subspecies of V. sativa.

The seeds showed intermediate amounts of eicosenoic acid. The highest value was found in the single $V$. leucantha sample, which was not reported in any previous publication except in a small amount, as related by Mao et al. (2015).

Erucic acid exerts negative effects on animal metabolism (Kuhnt et al. 2012). The presence of the erucic acid in vetch seeds was reported in some legumes, but not in vetch seed (Akpinar et al., 2001; Bagci et al., 2004). However, erucic acid was not detected either in the Tunisian vetch (Renna et al. 
(2014), or in the present work. No previously published data, in vetch seeds, reported the presence of the nervonic acid (an erucic acid derivative), that we detected in our samples.

From the other hand, a diet high in omega-9 could help to reduce the risk of developing cardiovascular disorders. In addition, since the ratio of omega-6/omega-3 is too high in modern diets, this gives another advantage to omega-9s. In our results, the only representative FA in omega 9 is the cis-11eicosenoic acid.

\section{PolyUnSaturated Fatty Acids (PUSFA)}

PUSFA have a role in the initial oxidative processes in which FA are transformed to carbohydrates. Conjugated linoleic acid (CLA) or other PUSFA have anti-carcinogenic, anti-thrombogenic and antiatherogenic properties. It is possible to increase CLA by increasing linoleic and linolenic acids in the feed as CLA are formed through isomerization of linoleic acid (Griinari et al. 2000). According to Hawke (1973), most of FA, mainly consists of palmitic, stearic, oleic, linoleic and linolenic acids, located in the chloroplasts. Their concentration varies among different environments, priamrily due to variation in PUSFA, of which linoleic and linolenic acids play an important role in maintaining membrane structure integrity (Lee and Cho 2012).

According to Meydani et al. (1991), linoleic acid is needed for a normal immune response. In the current study, linoleic acid amounts can reach 67.91\%. Pastor-Cavada et al. (2009b), and Bagci et al. (2004), reported that levels of linoleic acid reach $66.3 \%$ and $50 \%$ of TFA, respectively. Emre et al. (2011) demonstrated that linoleic acid content in vetch is greater than $45 \%$, while Akpinar et al. (2001), detected lowest linoleic acid content in Vicia taxa. In the same time, our results are consistent with those of several authors according to which, linoleic acid was usually found to be the most abundant FA in vetches and other legumes (Bagci et al. 2004; Pastor-Cavada et al. 2009b).

According to Renna et al. (2014), V. sativa subsp. amphicarpa and V. villosa present higher concentrations of linoleic acid compared to $V$. narbonensis, while intermediate values detected for the other seeds. Our results show that $V$. monantha subsp. calcarata, V. lutea, but especially $V$. leucantha present the most importqnt values of linoleic acid.

Our results show that linoleic acid is the predominant PUSFA, followed by linolenic acid, in the investigated taxa. The same findings were reported on Astragals, lupine and vetch (Emre et al. 2011; Renna et al. 2014).

Concerning linolenic acid, Akpinar et al. (2001) determined values of 1.9-9.2\%. Bagci et al. (2004) reported that linolenic acid content in the legume seeds generally found to be lower than $10 \%$. Linoleic and linolenic acids, the two major PUSFA detected in our taxa, are essential FA which cannot be synthesized de novo and are needed for optimum development and health. Linoleic acid was reported as the major FA in some Vicia taxa but more usually as the third most abundant USFA (after linoleic and oleic acids) in other vetch species; these results also occurred in our study.

In our results, linolenic acid was detected at low levels, comparing to linoleic and oleic acids. Oil should have a minimal amount of linolenic acid since the latter is considered as the first FA responsible for undesirable flavors in stored oils (Wolff and Kwolek 1971).

Several works reported the presence of $\alpha$-linolenic acid in oil obtained from Leguminosae (Renna et al. 2014). In vetch species, the content of this FA can reach $21.98 \%$, in Turkey and $9.77 \%$, in Tunisia. Many vetches were recognized to contain less than $15 \% \alpha$-linolenic acid in their seeds (Akpinar et al. 2001, Bagçi et al. 2004, Pastor-Cavada et al. 2009b). Exceptions regarded few species or varieties (Pastor-Cavada et al. (2009b; Bagçi et al., 2004). In our results, the presence of $\alpha$-linolenic acid was not detected.

No previous work reported the presence of $\gamma$-linolenic acid, which is the most important FA observed in a sample of $V$. monantha subsp. calcarata, and detected in 12 accessions. This FA acid possesses a therapeutic value. The presence of linolelaidic acid did not carry over into the literature. However, it 
has been detected in some of our samples. Other FA have been revealed as traces, as reported by Renna et al. (2014).

The highest value of $\mathrm{n} 6 / \mathrm{n} 3$ was observed in an accession of $V$. monantha subsp. calcarata and the lowest one in an accession of $V$. tenuifolia, which also has the highest level of linolenic acid. The latter was generally found to be lower than $10 \%$ in the legume seed oils. This observation applies to our results since the $10 \%$ rate was only exceeded for one of the 20 studied.

Previous study reported the presence of arachidonic acid in vetch oil seed with relatively low and comparable concentrations (Renna et al. 2014); which is not the case in our accessions.

According to Bagci et al. (2004), eicosadienoic acid was detected only in one out of six analyzed species. While, Akpinar et al. (2001) detected a large variation in the levels of this FA with a higher value of eicosadienoic acid if than those noticed in our study and by Renna et al. (2014).

Special attention must be given to the cis-4, 7, 10, 13, 16, 19 docosahexaenoic acid which has not been reported in the literature but which was found in an accession of $V$. narbonensis. Other FA (cis11, 14, 17-ecosatrienoic and cis-13, 16-docosadienoic acids) have not been reported in previous studies but have been observed as traces in our genotypes

Our results demonstrate the quality of the genotypes, which contain FA of great nutritional interest. Indeed, Omega 3-FA which rate can reach $12.187 \%$ in our taxa are PUSFA which have been associated with many health benefits. Among the omega-6s, only linoleic acid is described as "essential". The body uses omega-6 to develop highly USFA and eicosanoids series 1 and 2.

\section{Omega 6/Omega3}

The n6/n3 FA ratio is used to assess the nutritional value of lipids. An optimal n6/n3 FA ratio should vary between 1:1 and 4:1, but Western diets may reach ranges of 10:1 to 20:1 (Simopoulos 2011), which corresponds to the values found in some of our accessions.

\section{Environment influence}

Our study shows qualitative and quantitative differences between taxa and even between accessions of the same taxon. Much dissimilarity between our results and those of other works have been observed. Obviously, several factors, such as genetics, geographical location, climatic settings and growing conditions may affect the FA content in the seed oils. Akpinar et al. (2001) reported that variations in the ecogeographical zones may also have exerted a key role as the environment can significantly affect the synthesis of FA. Murcia and Rincon (1992) reported that FA composition is influenced by agro-climatic conditions as the enzymes in FA biosynthesis depend on these factors. Environmentalbased factors could contribute significantly to the observed differences as our accessions were collected from different regions.

According to Mao (2012), highest lipid and USFA contents were found in taxa characterized by lower accumulated temperature $\left(\geq 10^{\circ} \mathrm{C}\right)$ in the region. In our results, the highest lipid and USFA contents were observed in genotypes collected from stations characterized by cool winter. Plants increase the contents of lipids and USFA as a response to the drop in temperatures. During the process of cold accumulation, FA desaturases convert stearic acid to linolenic acid through oleic acid and linoleic acid intermediates (Falcone et al. 2004).

The higher content of SFA was observed in a sample collected in a station with warm winter. According to Lee and Cho (2012), the high temperature environment induces a rise of SFA which could be explained by lipid peroxidation accompanied by a simultaneous decrease of USFA. Similarly, Larkindale and Huang (2004) reported that the increase in SFA could enhance membrane rigidity, thus maintain membrane integrity under the high temperature environment.

Phylogenetic relationships 
Bagci et al. (2004) reported that FA profiles can be used as a good chemotaxonomic marker for Fabaceae in general and for the genus Vicia in particular. The FA profiles obtained highlighted both inter and intraspecific variability. Apart from a few isolated cases, genotypes of the subgenus Vicilla and the section Cracca tend to cluster together. Similarly, accessions of the subgenus Vicia also tend to cluster together.

These results correspond to those of our previous works (Bechkri and Khelifi 2016, Bechkri and Khelifi 2017 a, b, Bechkri et al. 2018, Bechkri et al. 2019), where the separations were sufficient on the sectional level and where the species of sativa exhibited a set of taxa with an overlap. According to Abozei et al. (2017), all species from section Cracca clustered together, using FA profiles showing a close relationship among the section members.

It is very important to emphasize that the accessions of the Narbonensis section (represented by $V$. narbonensis) bind to the accessions of the Vicia section (represented by $V$. sativa). This result is also reported by Schaefer et al. (2012).

We highlight the particularity of $V$. leucantha, which is far from the other accessions because of its particular content in FA. It also has the highest level of linoleic acid, as well as the highest USFA/SFA ratio. These results were not obtained by previous works. This genotype is among the samples that show a high oil yield compared to the others. According to Liu (2011), the differences in changing intensity of FA composition among grain species correspond to those in oil distribution in the seed, while a varietal difference in distribution patterns and the FA composition of lipids within the species were insignificant.

It is important to mention that the accessions of the first cluster belong to the same bioclimatic stage. But in the other clusters, the genotypes that are found together belong to different bioclimatic stages (Bechkri and khelifi 2016, 2017a, 2017b). At the same time, the smallest clustering distance was obtained between samples collected from the same city, characterized by a cool winter. Thus there is no clear relationship between the grouping of samples according to their content in FA and their geographical origin.

\section{Conclusion}

In this study, vetch seed oils were rich in palmitic, stearic, oleic, linoleic and linolenic acids. Despite the small proportion of lipids present in legumes seeds, their profiles indicate the desirable nature of FA present. It is very likely that this content is influenced by the land type, altitude and an average temperature in the growing location. Obtained results might provide contributions on the chemotaxonomic and phylogenetic relationships. However, due to the high level of crossbreeding in vetch taxa, the FA profile cannot be used as a tool for taxonomic determination at specific level, but, it reflects the subgeneric and sectional affinities. The evaluation of FA in a wider range of Vicia taxa is suggested to characterize the chemotaxonomic and phylogenetic relationships both on intra and interspecific levels, especially in sativa complex. The possible toxic effect should also be kept in mind and other compounds related to nutritional quality should be investigated.

\section{References}

Akpinar N. Akpinar MA. Turkoglu S. 2001. Total lipid content and fatty acid composition of the seeds of some Vicia L. species. Food chemistry 74: 449-453

Aliferis KA. Cubeta MA. Jabaji. 2013. Chemotaxonomy of fungi in the Rhizoctonia solani species complex performing GC/MS metabolite profiling. Metabolomics (9) : 159-169

Alves SP. Cabrita ARJ. Fonseca AJM. Bessa RJB. 2008. Improved method for fatty acid analysis in herbage based on direct transesterification followed by solid-phase extraction. J. Chromatogr. A $1209: 212-219$

Andrzejewska J. Ignaczak S. Barzyk P. 2016. Oil content and fatty acid profile in seeds of Polish breeding lines and cultivars of legumes. Acta Scientiarum Polonorum. Agricultura 15(2) : 3-13 
Bagci E. Ludger B. Ozçelik H. Aitzemuller K. Vural M. Sahin A. 2004. A study of the fatty acid and tocochromanol patterns of some Fabaceae (Leguminosae) plants from Turkey. I. Grass Y Aceit. 4 : 378-384

Bakoglu A. Kokten K. Kilik O. 2017. Seed fatty acid composition of some Fabaceae taxa from Turkey. a chemotaxonomic approach. Progress in nutrition 19(1) : 86-91

Bechkri S.. Khelifi D. 2016. Variation in Vicia sativa s.l from Algeria based on morphological characters and ecogeographic parameters. Genetic Resources and Crop Evolution.64:815-832.

Bechkri S. Medoukali I. Khelifi D. 2017a. Phylogenetic relationships between and Within 11 taxa of genus Vicia from Algeria based on evidence from isozymes and physical seed properties. European Scientific Journal 13 (9)

Bechkri S. Medoukali I. Khelifi D. 2017b. Ecogeographic variability and genetic diversity associated with seed albumins, globulins and prolamins patterns in Vicia taxa from Algeria. Botanical studies. $58: 27$

Bechkri S. Medouri A. Chekara-Bouziani M. Khelifi D. 2018. The determination of sectional and sub-generic relationships among Vicia taxa from Algeria using plant morphology and ISSR markers. Acta Scientific Agriculture. 2 (9): 2-10

Bechkri S. Boutekrabt L. Khelifi D. 2019. Characterization of 7 Vicia L. taxa from Algeria based on evidence from morphology and ecogeography. Agrobiologia 9(2): 1568-1580

Belury MA. 2002. Dietary Conjugated Linoleic Acid in health: Physiological Effects and Mechanisms of action. Annu. Rev. Nut $22: 505-31$

Emre I. Sahin A. Yilmlaz O. Genç H. Bahsi M 2011. Composition of seed fatty acids in some Vicia L. taxa from Turkey. Acta Botanica Gallica, 158(4) : 493-498

Falcone DL. Ogas JP. Somerville CR. 2004. Regulation of membrane fatty acid composition by temperature in mutants of Arabidopsis with alterations in membrane lipid composition. Plant Biol. 4,17

Griinari JM. Corl BA. Lacy SH. Chouinard PY. Nurmela KVV. Bauman DE. 2000. Conjugated linoleic acid is synthesized endogenously in lactating dairy cows by $\Delta 9$-desaturase. The journal of nutrition 130(9) : 2285-2291

Hawke JC. 1973. Lipids. In: Butler U.W. and Bailey R.W. (eds) Chemistry and biochemistry of herbage, Academic Press, London, UK, pp. 213-263.

Higuchi M. Terao J. Jwai K. 1982. Gas chromatography-mass spectrometric determination of fatty acid in seed oil of winged bean (Psophocarpus tetragonolobus (L.) DC. J. of Nutritional science and vitaminology $28: 511-518$

Holman RT. 1981. Essential fatty acids in nutrition and disease. Chemistry and industry 21 : 704-709

Kaplan M. Kokten K. Uzun S. 2014. Fatty acid and metal composition of the seeds of Vicia ervillia varieties from Turkey. Chemistry of natural compounds 50 (1): 117-119

Kuhnt K. Degen C. Jaudszus A. Jahreis G. 2012. Searching for health beneficial n-3 and n-6 fatty acids in plant seeds. Eur. J. Lipid Sci. Tech. $114: 153-160$

Larkindale J. Huang B. 2004. Changes of lipid composition and saturation level in leaves and roots for heat-stressed and heat-acclimated creeping bentgrass (Agrostics stolonifera). Environ. Exp. Bot. $51: 57-67$

Lee JH. Cho KM. 2012. Changes occuring in compositional components of black soybeans maintained at room temperature for different storage periods. Food Chem. 131:161-169

Liu K. 2011. Comparison of Lipid Content and Fatty Acid Composition and Their Distribution within Seeds of 5 Small Grain Species

Lopes AR. Baptista M. Dionisio G. Rosa I. Paula JR. Gomes-Pereira J. Figueriredo C. Bandarra N. Calado R. Rosa R. 2016. " Gone with the winnd : Fatty acid biomarkers and chemotaxonomy of stranded pleustonic hydrozoans (Velella velella and physalia physalis). Biochem. Systematic and Ecology $66: 297-306$

Mao ZX. Fu H. Nan ZB. Wan CG. 2015. Fatty acid, amino acid, and mineral composition of four common vetch seeds on Qinghai-Tibetan plateau. Food chemistry $171: 13-18$ 
Meydani SN. Lichtenstein AH. White PJ. Goodnight SH. 1991. Food use and health effects of soybean and sunflowers oils. J. Am. Coll. Nutr. $10: 406-28$

Pastor Cavada E. Juan R. Pastor JE. Alaiz M. Vioque J. 2009b. Fatty acid distribution in the seed flour of wild Vicia species from Southern Spain. J. Am. Oil Chem. Soc. 86 : 977-983

Pirman T. Stibilj V. 2003. An influence of cooking on fatty acid composition in three varieties of common beans and in lentil. European Food Research and Technology 217-6) : 498-503

Renna M. Gasmi-Boubaker. Lussiana C. Battaglini LM. Belfayez Kh. Fortina R. 2014. Fatty acid composition of the seed oils of selected Vicia L. taxa from Tunisia. Italian journal of animal science. 13(2):3193

Schaefer H. Hechenieitner P. Santos-Guerra A. Menezes de Sequeira M. Pennington RT. Kenicer G. Carine MA. 2012. Systematics, biogeography and character evolution of the legume tribe Fabeae with special focus on the middle-Atlantic Island lineages. BMC Evol. Biol. $12: 250$

Simopoulos AP. 2011. Importance of the omega-6/omega-3 balance in health and disease: evolutionary aspects of diet. In : A.P Simopolous (ed.) Healthy agriculture, healthy nutrition, healthy people. Karger, Basel, Switzerland, pp 10-21

Wolff IA. Kwolek WF. 1971. Lipids of the Leguminosae. In Chemotaxonomy of the Leguminosae, 231-2551 (Eds Harborne JB, Boulter D, Turner BL). London : Academic Press. 